Aim The ambulance service (EMS) and out-of-hours service $(\mathrm{OOH})$ of Capital Region of Copenhagen (EMS Copenhagen) was united January 1st 2014, featuring only two phone numbers to call in case of acute illness or injury: 112 for life threatening conditions, and 1813 for non-urgent conditions. All prehospital access to in-hospital acute care is pre-assessed and guided to the nearest appropriate hospital with least waiting time (capacity controlling). The aim of this study was to describe citizens' utilisation and satisfaction with the Copenhagen-Model (CM).

Methods Data was delivered by the Emergency Departments (ED) database and the internal database for EMS Copenhagen. Utilization-analysis of $\mathrm{OOH}$ and $\mathrm{ED}$ components before (2013) and after (2014-2015) implementation of the new structure was examined. Satisfaction-analysis with the CM was evaluated by an external facility April 1st to October 1st (2171 questionnaires - response-rate 36\%).

Results The $\mathrm{OOH}$ service (1.8 million inhabitants) receives approx. 265 calls/1000 citizens annually. The introduction of the CM resulted in a decrease of contacts to the ED 566606 contacts in 2013 to 516738 and 497389 contacts in 2014 and 2015, respectively $(\mathrm{p}<0.05)$. Capacity controlling showed that citizens referred to ED for emergency triage had an average time from call to treatment-start of $62 \mathrm{~min}$ (nonurgent $93 \mathrm{~min}$ ). Approx. 93\% of callers to the $\mathrm{OOH}$ had a good-very good experience with the service.

Conclusion EMS capacity controlling for non-urgent conditions showed a significant decrease in ED contacts, and has proven successful with $93 \%$ of callers having a good-very good experience with the service.

Conflict of interest None declared.

Funding EMS Copenhagen receives centre support from The Laerdal Foundation. The corresponding author has received grants from Trygfonden. Non of these organisations have had any influence on the study.

\section{MACHINE LEARNING - A NOVEL APPROACH TO INCREASE RECOGNITION OF OUT OF HOSPITAL CARDIAC ARREST DURING CALLS TO EMERGENCY MEDICAL DISPATCH CENTRES}

${ }^{1,2} \mathrm{NF}$ Blomberg*, 1,2F Folke, 1,2TP Møller, 1,2F Lippert. 'Emergency Medical Services Copenhagen, Ballerup, Denmark; ${ }^{2}$ University of Copenhagen, Denmark

\subsection{6/bmjopen-2017-EMSabstracts.25}

Aim The chance of surviving Out of Hospital Cardiac Arrest (OHCA) is highly correlated with medical dispatchers' recognition of the condition during emergency calls. The median sensitivity for OHCA recognition across studies is around $70 \%$. (1) This leaves room for improvement. A novel approach is to improve recognition of OHCA by applying Machine Learning directly on the call-dialogue. The aim of the study is to investigate if recognition can be increased by use of Machine Learning.

Methods Our study used 489 emergency calls regarding OHCA received at the Emergency medical Dispatch Centre Copenhagen (EMDC) in 2013 and a control group of 571 non-OHCA calls. All calls were transcribed and then divided into two datasets, one for training the machine learning model (275 OHCA-calls, 361 non-OHCA calls), and one for testing the model. The Machine Learning model automatically detected patterns and predictive word contexts in relation to
OHCA/non-OHCA. The model identified words associated with OHCA, and was able to determine whether a call was regarded as OHCA.

Results The Machine Learning model reached a sensitivity of 95.3\% on 214 transcribed OHCA-calls (204 true positive/10 false negative) and a control group of 210 non-OHCA calls. Specificity for the Machine Learning model was 99.0\%.

Conclusion These early results show that a Machine Learning model based on neural networks has potential to improve recognition of OHCA. The results are thought-provoking and invites to further research.

\section{REFERENCE}

1. Viereck S, Moller TP, Rothman JP, Folke F, Lippert F. Recognition of out-of-hospital cardiac arrest during emergency calls - a systematic review of observational studies. 2017. Ref Type: Submitted article in review

Conflict of interest None declared.

Funding Emergency Medical Services Copenhagen has received an unrestricted research grant from the Laerdal Foundation.

\section{SYSTEMATIC INFLUENCES OF THE IMPLEMENTATION OF A COMPREHENSIVE 24/7-TELEMEDICINE SYSTEM INTO EMERGENCY MEDICAL SERVICE}

${ }^{1,2}$ SK Beckers*, 'S Bergrath, ${ }^{1} \mathrm{~F}$ Hirsch, ${ }^{1,2} \mathrm{M}$ Felzen, ${ }^{1} \mathrm{R}$ Rossaint. ${ }^{1}$ Department of Anaesthesiology, University Hospital Aachen, RWTH Aachen University; ${ }^{2}$ Medical Direction, Emergency Medical Service, City of Aachen, Germany

\subsection{6/bmjopen-2017-EMSabstracts.26}

Aim Demographic changes, decreasing availability of general practitioners, and at least regional shortage of qualified emergency medical service (EMS) physicians led to increasing arrival times and quality problems. Telemedical solutions could help to solve some of the problems.

Methods Overall safety and feasibility of prehospital telemedically guided care was already proven in two research projects from 2007 to $2013 .^{1-3}$ Their results led to implementation of a multifunctional mobile telemedicine system in the city of Aachen, Germany. From 04/2014 to 03/2015 all ambulances were equipped with a telemedicine system connected to a teleconsultation centre staffed with anesthesiologists experienced in emergency care. Audio, real-time vital data, 12-lead-ECG, picture transmission, and video streaming from ambulances was accomplished with encrypted and parallelized transmission using. Mission numbers prior and after implementation were compared to evaluate systematic influence.

Results From 04/2014 to 06/2016 overall 4.901 EMS missions were supported and guided telemedically: $n=4.151$ emergency missions $(85 \%)$ and $\mathrm{n}=750 \quad(15 \%)$ inter-hospital transfers. Prior to implementation (04/2013-03/2014) 17.305 solely ambulance missions (68.7\%) and 7.882 ambulance plus EMS physician unit missions were performed (31.3\%). After implementation (04/2015-03/2016) 20.102 ambulance missions $(76 \%)$ and 6.360 ambulance plus EMS physician missions (24\%) were conducted which revealed a significant difference between both phases, $\mathrm{p}<0.0001$.

Conclusion The implementation of a telemedicine system into routine care led to a significant decrease in conventional onscene physician missions as well as to an overall decrease in physician guided EMS cases. Therefore, the approach can be judged resource optimising and holds a potential for economic 
improvements although highly qualified physicians carry out the service.

\section{REFERENCES}

1. Brokmann JC, Conrad C, Rossaint R, Bergrath S, Beckers SK, Tamm M, Czaplik M, Hirsch F. Treatment of acute coronary syndrome by telemedically supported paramedics compared with physician-based treatment of acute coronary syndrome: a prospective, interventional, multicentre trial. J Med Internet Res 2016;18(12): e314doi:10.2196/jmir.6358

2. Felzen F, Brokmann JC, Beckers SK, Hirsch H, Tamm M, Rossaint R, Bergrath S Technical performance of a multifunctional prehospital telemedicine system in routine emergency medical care - an observational study. Journal of Telemedicine and Telecare 2016; pii: 1357633X16644115.

3. Bergrath $S$, Reich $A$, Rossaint $R$, Rörtgen $R$, Gerber J, Fischermann $H$, Beckers SK, Brokmann JC, Schulz JB, Leber C, Fitzner C, Skorning M. Feasibility of Prehospital Teleconsultation in Acute Stroke - a pilot study in clinical routine. PLOS ONE 2012;7(5):e36796

Conflict of interest None declared.

Funding None declared.

\section{IMPLEMENTATION, TEMPORAL CHANGES, AND FOLLOW-UP OF A NATIONWIDE AED-NETWORK}

LIM Karlsson*, ${ }^{1} \mathrm{CM}$ Hansen, ${ }^{1} \mathrm{M}$ Wissenberg, ${ }^{2} \mathrm{SM}$ Hansen, ${ }^{3} \mathrm{FK}$ Lippert, ${ }^{1} \mathrm{~S}$ Rajan, ${ }^{2} \mathrm{~K}$ Kragholm, ${ }^{2} \mathrm{~S}$ Møller, ${ }^{1,4} \mathrm{GH}$ Gislason, ${ }^{2} \mathrm{C}$ Torp-Pedersen, ${ }^{1,3} \mathrm{~F}$ Folke. ${ }^{1}$ Department of Cardiology, Copenhagen University Hospital Gentofte, Denmark; ${ }^{2}$ Departments of Clinical Epidemiology and Cardiology, Aalborg University Hospital, Denmark; ${ }^{3}$ Emergency Medical Services Copenhagen, the Capital Region of Denmark; ${ }^{4}$ National Institute of Public Health, University of Southern Denmark, Copenhagen

\subsection{6/bmjopen-2017-EMSabstracts.27}

Aim To describe the temporal development of automated external defibrillator (AED) deployment in Denmark according to type of AED location and accessibility.

Methods We collected information on all AEDs registered in the nationwide Danish AED network, 2007-2015, including type of AED location, accessibility 24 hours a day (24/7), and year of deployment.

Results The number of registered AEDs available for public access defibrillation increased from 140 in 2007 to 12666 in 2015. In total, 14,390 AEDs were registered during the study period. Of these, most AEDs were placed in companies/offices (29.3\%, $\mathrm{n}=4,213)$, followed by school/education facilities (12.6\%, $n=1,819)$, and sport facilities $(10.2 \%, n=1,464)$ whereas few AEDs were deployed in residential areas $(6.9 \%$, $\mathrm{n}=999)$ and transportation facilities $(1.0 \%, \mathrm{n}=147)$. In 2007 and 2008, most AEDs were placed in sports facilities but then declined. From 2009 and forward, most AEDs were placed in companies/offices, whereas deployment in residential areas showed a temporal increase. AED accessibility 24/7 increased from $11.4 \%$ in 2007 to $35.2 \%$ in 2015 , with residential areas having the highest $24 / 7$ accessibility $(83.2 \%, n=758)$, followed by churches/community centres $(74.5 \%, \mathrm{n}=301)$, and transportation facilities $(69.0 \%, \mathrm{n}=87)$. Despite AED deployment was highest in companies/offices only $14.8 \% \quad(n=542)$ of these AEDs were accessible 24/7.

Conclusion The number of public available AEDs in Denmark has markedly increased from 2007-2015, with companies/offices, school/education facilities, and sport facilities as most frequent places of AED deployment. However, only $14.8 \%$ of AEDs placed at companies/offices had 24/7 accessibility.

Conflict of interest None declared.

Funding Dr. Karlsson is supported by a fund from The Danish foundation TrygFonden, who has no influence on study design; in the collection, analysis, or interpretation of data.
28 THE DIFFERENCE BETWEEN PHYSICIAN ASSISTANTS AND AMBULANCE NURSES AS SOLO EMERGENCY CARE PROVIDERS IN EMS, A CROSS SECTIONAL STUDY

$S$ Berben*, ${ }^{1} A$ Bloemhoff, ${ }^{2} \mathrm{~L}$ Schoonhoven, ${ }^{3} \mathrm{~A}$ de Kreek, ${ }^{4} \mathrm{P}$ van Grunsven, ${ }^{5} \mathrm{M}$ Laurant. ${ }^{1}$ Eastern Regional Emergency Healthcare Network, Radboud University Medical Centre, Nijmegen, the Netherlands; ${ }^{2}$ Faculty of Health Sciences, University of Southampton, Southampton, UK; ${ }^{3}$ Ambulance Emergency Medical Service Veiligheids en Gezondheidsregio Gelderland-Midden, Arnhem, the Netherlands; ${ }^{4}$ Ambulance Emergency Medical Service Veiligheidsregio Gelderland-Zuid, Nijmegen, the Netherlands; ${ }^{5}$ Scientific Institute for Quality of Healthcare, Radboud University Medical Centre, Nijmegen, Netherlands

\subsection{6/bmjopen-2017-EMSabstracts.28}

Aim The aim of the study is to compare the assessment, treatment, referral, and follow up contact with the dispatch centre of emergency patients treated by the physician assistant (PA) and ambulance nurse (RN) in emergency medical services (EMS) in the Netherlands.

Methods In a cross-sectional document study in two EMS regions we included 991 patients, treated by two PAs $(n=493)$ and 23 RNs $(n=498)$. Data were drawn from predefined and free text fields in the electronic patient records and analysed using descriptive statistics. We used $\chi 2$ and Mann-Whitney U tests to analyse for differences in outcome of care. Statistical significance was assumed at a level of $\mathrm{p}<0.05$.

Results In line with the medical education, PAs used a medical diagnostic approach $(16 \%, \mathrm{n}=77)$ and an exam of organ tract systems $(31 \%, \mathrm{n}=155)$. PAs consulted more often other medical specialists $(33 \%)$ than RNs $(17 \%) \quad(\chi 2=35.5, \mathrm{p}<0.0001)$. PAs referred less patients to the general practitioner (GP) or emergency department (ED) (50\%) compared to RNs (73\%) $(\chi 2=52.9, \mathrm{p}<0.0001)$. Patient follow up contact with the dispatch centre within 72 hour after completion of the emergency care on scene showed no variation between PAs (5\%) and RNs (4\%).

Conclusion PAs seemed to operate from a more general medical perspective. They referred significantly less patients to the ED.

\section{REFERENCES}

1. Bloemhoff, et al. Scandinavian Journal of Trauma, Resuscitation and Emergency Medicine 2016:24:86.

2. Affiliation of presenting author is Eastern Regional Emergency Healthcare Network, Radboud University Medical Centre, Nijmegen, the Netherlands

Conflict of interest None declared.

Funding Ministery of Health Welfare and Sports, the Netherlands

\section{INVESTIGATING THE POPULATION CHARACTERISTICS, PROCESSES AND OUTCOMES OF PRE-HOSPITAL PSYCHIATRIC AND SELF-HARM EMERGENCIES IN SCOTLAND: A NATIONAL RECORD LINKAGE STUDY}

${ }^{1}$ E Duncan*, ${ }^{1} \mathrm{C}$ Best, ${ }^{2} \mathrm{~N}$ Dougall, ${ }^{1} \mathrm{~S}$ Skar, ${ }^{3} \mathrm{D}$ Fitzpatrick, ${ }^{1} \mathrm{~J}$ Evans, ${ }^{4} \mathrm{~A}$ Corfield, ${ }^{5}$ I Goldie, ${ }^{1} \mathrm{M}$ Maxwell, ${ }^{6} \mathrm{H}$ Snooks, ${ }^{7} \mathrm{C}$ Stark, ${ }^{5} \mathrm{C}$ White, ${ }^{8} \mathrm{~W}$ Wojcik. ${ }^{1}$ University of Stirling; ${ }^{2}$ Edinburgh Napier University; ${ }^{3}$ Scottish Ambulance Service; ${ }^{4}$ NHS Greater Glasgow and Clyde; ${ }^{5}$ Mental Health Foundation; ${ }^{6}$ Swansea University; ${ }^{7}$ NHS Highland; ${ }^{8}$ NHS Lothian

\subsection{6/bmjopen-2017-EMSabstracts.29}

Aim To investigate the demographic characteristics, care pathways, and clinical and service outcomes of people who present to ambulance services with a psychiatric or self-harm emergency 